\title{
A memória histórica do regime militar ao longo de três gerações no Rio de Janeiro:
}

sua estrutura representacional ${ }^{1}$

\section{Historical memories of the Brazilian military regime \\ in Rio de Janeiro across three generations: \\ a representational structure}

\author{
Celso Pereira de $\mathbf{S A ́}^{2}$ \\ Denize Cristina de OLIVEIRA $^{3}$ \\ Ricardo Vieiralves de CASTRO \\ Renata VETERE \\ Rafael Vera Cruz de CARVALHO²
}

\begin{abstract}
Resumo
São apresentados e discutidos resultados de uma pesquisa sobre a memória e as representações sociais do Regime Militar no Rio de Janeiro. Os dados consistiram em associações livres a partir do termo indutor "Regime Militar", produzidas e hierarquizadas por duzentos adultos que vivenciaram aquele período quando eram jovens, 202 idosos, que o vivenciaram já adultos, e 432 jovens, que não chegaram a testemunhá-lo. A análise dos dados envolveu uma combinação entre a frequência dos temas evocados e a ordem de importância a eles atribuída. Os resultados relativos aos três conjuntos etários são nitidamente diferentes. Os adultos exibem uma memória concisa, consistente e crítica; os idosos mostram-se menos consistentes e menos críticos; os jovens parecem mais críticos que os adultos, mas de forma dispersa e imprecisa. A análise de cada conjunto etário evidenciou diferenças estatisticamente significativas entre as contribuições dos subconjuntos de diferentes orientações políticas e de diferentes níveis de escolaridade.
\end{abstract}

Unitermos: Gerações. Memória. Percepção sociais.

\section{Abstract}

The present work presents and discusses the results of a study into the memories and the social representations of the Military Regime in Rio de Janeiro. Data consisted of free associations based on the prompting term "Military Regime", produced and ranked in order of importance

- Parte do projeto Análise psicossocial da memória histórica de regimes políticos brasileiros, desenvolvido no Programa de Pós-Graduação em Psicologia Social da Universidade do Estado do Rio de Janeiro, com apoio do Conselho Nacional de Desenvolvimento Científico Tecnológico (Proc. 303021/2004-7) e da Fundação de Amparo à Pesquisa do Estado do Rio de Janeiro (Proc. 171.075/2005).

2 Universidade do Estado do Rio de Janeiro, Instituto de Psicologia, Departamento de Psicologia Social e Institucional, Programa de Pós-Graduação em Psicologia Social. R. São Francisco Xavier, 524, 20559-900, Rio de Janeiro, RJ, Brasil. Correspondência para/Correspondence to: C.P. SÁ. E-mail: <sa.celso@gmail.com>.

3 Universidade do Estado do Rio de Janeiro, Faculdade de Enfermagem, Departamento de Fundamentos de Enfermagem. Rio de Janeiro, RJ, Brasil. Agradecimento: a participação, no projeto, de Juliana Aieta Perez, bolsista de AT/CNPq e da Fundação de Amparo à Pesquisa do Estado do Rio de Janeiro. 
by 200 adult subjects who lived through this period when they were young, 202 elderly subjects who experienced it as adults, and 432 young people who never witnessed it. Data analysis involved a combination of the frequency of the themes evoked and the order of importance attributed to them. The results of the three age groups are markedly different. Adults exhibited a concise, consistent and critical memory; the more elderly demonstrated less consistency and less criticism; young people seem more critical than adults, but in a loose and imprecise fashion. The analysis of each age group evidenced statistically significant differences among the contributions of those subsets with different political orientations and with different levels of education.

Uniterms: Generations. Memory. Social perception.

Completaram-se já quatro décadas desde o início do Regime Militar instaurado no Brasil em 1964 e, desde o seu término, em 1985, passaram-se duas décadas. A partir de então, apesar de a primeira eleição de um presidente civil ter sido indireta e o primeiro presidente civil eleito diretamente pelo povo não ter correspondido às suas expectativas, o país tem vivido uma democracia plena.

O período de exceção representado pelo Regime Militar conta hoje com uma história escrita de extensão e relevância consideráveis, na qual se incluem trabalhos não só de historiadores, mas também de jornalistas, cronistas e analistas políticos, como Dreifuss (1981), Moreira Alves (1984), Gorender (1987), Ventura (1988), D’Araújo, Soares e Castro (1994), Gaspari (2002a, 2002b, 2004a, 2004b), entre outros. Os manuais de história, como os de Skidmore (1998) e Santos, Neves, Machado e Gonçalves (2002), descrevem igualmente os principais fatos do período, embora de forma menos crítica e com menor riqueza de detalhes.

Na linguagem corrente, diz-se que há um esforço de "preservação da memória"daquele período, mas isso pode soar verdadeiro apenas quando se confunde a história com a memória. As diferenças entre elas têm sido apontadas tanto por sociólogos pioneiros no estudo da memória social, como Halbwachs (1950/2004), quanto por historiadores contemporâneos críticos da própria história, como Nora (1997), além de psicólogos sociais que, como Jodelet (1992), estudam o papel que condicionantes sociais (como a comunicação de massa) desempenham na construção da memória de fatos históricos.

Nesse último sentido, Sá $(2005,2007)$ propõe chamar de "memória histórica" a memória social que, além de alimentada pelo próprio testemunho dos fatos ou pelo relato de quem os tenha vivido, constrói-se adicional ou alternativamente a partir de documentos e de outros tipos de registros do passado, bem como da transmissão oral corrente dos acontecimentos e práticas do passado. Os produtos da história escrita ou oral, configuram-se como uma das fontes da memória histórica, sob as condições de que eles sejam efetivamente lidos ou ouvidos pelas pessoas e de que estas e os grupos a que pertencem sejam suficientemente impressionadas pelos documentos ou pelos relatos orais, a ponto de incorporá-los à sua memória.

A noção de documento empregada nesta "psicologia social da memória" é provavelmente mais ampla do que aquela dos historiadores, abrangendo tanto os documentos stricto sensu (como os chamados"arquivos da ditadura", ainda não abertos de fato à população) quanto as crônicas e os livros didáticos antes mencionados, as matérias veiculadas pela mídia, os monumentos, os eventos comemorativos e as produções culturais, entre elas, os filmes cinematográficos. No caso do Regime Militar, essas fontes potenciais para a construção das memórias em um nível comum ou coletivo são de produção bastante escassa, ou então não se encontram disponíveis em escala social condizente com o tamanho, a natureza diversificada e os recursos tanto econômicos quanto culturais da população brasileira.

Assim, se a história do Regime Militar não corresponde necessariamente à sua memória e se, além disso, um eventual cultivo de tal memória não pode ser inferido a partir de fontes documentais porque estas não se encontram amplamente acessíveis à população, o que existe então como "construção da memória" desse período (e não apenas como "preservação")? Quais são, hoje em dia, os seus conteúdos descritivo, afetivo e valorativo? E por quais meios pode-se buscar evidenciá-los?

A resposta a essas perguntas remete à investigação característica da psicologia social, ou seja, é preciso verificar junto às pessoas o quanto elas lembram e do que em especial se lembram em relação ao Regime Militar. É importante, ainda, em termos da memória social 
histórica, identificar a existência de lembranças que sejam apenas comuns e de outras que sejam ativamente compartilhadas em determinados conjuntos ou estratos sociais. De especial relevância é comparar os conteúdos que predominam na memória de conjuntos sociais de diferentes idades, os quais, em função dessa diferença, tenham sido testemunhas dos fatos quando já adultos ou quando ainda jovens, ou sequer tenham vivido durante aquele período.

A pesquisa que embasou este artigo dedicou-se a descrever os conteúdos das memórias históricas construídas em cada um dos três grupos etários mencionados, analisá-las comparativamente e identificar as diferenças que existem no âmbito de cada grupo em função do nível de escolaridade e da orientação política dos seus componentes. $\mathrm{O}$ artigo provê um relato apenas parcial da pesquisa desenvolvida, com ênfase para uma determinada articulação teórico-metodológica, ficando a análise dos resultados que a complementam para uma publicação posterior.

\section{Um recorte teórico-conceitual}

A construção do objeto da pesquisa (Sá, 1998) deu-se a partir da articulação entre três principais linhas de proposições conceituais e teóricas, selecionadas dentre as que têm sido mais proveitosamente apropriadas pela psicologia social da memória.

Em primeiro lugar, justificando a seleção de três diferentes estratos etários para comparar suas respectivas memórias históricas do Regime Militar, privilegia-se a proposição da existência de um período crítico de maior retenção das experiências vividas, que varia entre os 12 e os 25 anos de idade, ou seja, entre o início da adolescência e o fim da juventude ou início da vida adulta. Esta proposição é sustentada empiricamente por autores vinculados ao que se chamou de "psicologia social de origem cognitivo-naturalista" como Conway (1995, 1998), Pennebaker e Basanick (1998), Schuman, Belli e Bischoping (1998) e Sá (2008), e é explicitamente derivada do tratamento teórico-conceitual dado por Mannheim (1952/1982) ao "problema sociológico das gerações".

O conjunto etário que viveu sua juventude durante a vigência do Regime Militar, independentemente das classes sociais de origem dos seus membros ou do pertencimento destes a diferentes grupos sociais concretos, encontrou-se em uma "situação de geração" bem definida, como caracterizada por Mannheim (1952/1982). Tal situação foi bastante diversa tanto daquela dos que testemunharam esse período histórico após terem concluído o seu próprio processo de definição geracional ocorrido, a propósito, durante outro regime político nacional conturbado e polêmico, a Era Vargas - quanto da situação em que está atualmente se formando a geração dos que nasceram após o término do Regime Militar. A distinção feita por Mannheim (1952/1982) entre"memórias adquiridas" pessoalmente e"memórias apropriadas" de outras pessoas, associada à noção de período crítico de aquisição de uma memória geracional, sugeriram que as lembranças acerca do mesmo regime político pudessem apresentar diferenças entre os sujeitos dos três estratos etários selecionados para o estudo. Por outro lado, isso não implicaria homogeneidade nas lembranças dentro de cada grupo, pois, como observa Mannheim (1952/1982) a propósito da existência de unidades de pensamento e memória diferenciadas em uma mesma geração:"os jovens que vivenciam os mesmos problemas históricos concretos fazem parte da mesma geração real; enquanto aqueles grupos dentro [dela], que elaboram o material de suas experiências comuns através de diferentes modos específicos, constituem unidades de geração separadas" (p.87).

Em segundo lugar, a investigação da memória histórica do Regime Militar foi equacionada em termos da pesquisa das suas representações sociais pelos três conjuntos considerados, a partir de uma proposição formulada por Jedlowski (2001), em sua releitura da obra pioneira de Halbwachs (1925/1994, 1950/2004). Segundo Jedlowski (2001), a memória coletiva pode ser definida como "um conjunto de representações sociais acerca do passado que cada grupo produz, institucionaliza, guarda e transmite através da interação de seus membros" (p.33).

A memória coletiva a que se refere Jedlowski (2001) é, por definição, a memória de um grupo social, da mesma forma que uma representação social como definida por Moscovici $(1976,1984)$ e Jodelet $(1984,1989)$ tem obrigatoriamente um grupo como sujeito produtor e/ou usuário. Por outro lado, a memória histórica, como aqui conceituada (Sá, 2005, 2007), é uma memória social 
da história, que pode ser constituída pelas memórias comuns a um conjunto amplo de pessoas que tenham sido expostas aos mesmos fatos ou informações. Esses fatos e informações, entretanto, podem também ser objeto de elaborações discursivas em grupos sociais mais restritos e alimentar, assim, memórias coletivas diversas. Uma memória histórica geracional pode ser vista como a reunião complexa das memórias comuns - adquiridas ou apropriadas dos participantes de uma situação de geração e das memórias coletivas que grupos concretos desses participantes tenham construído, não sendo incomum que as representações que compõem uma ou algumas destas memórias coletivas adquiram predominância sobre as demais e se difundam mais amplamente no seio de uma dada geração.

Em terceiro lugar, a pesquisa das representações sociais do Regime Militar, embora não seja fundamentada teoricamente apenas na chamada abordagem estrutural (Abric, 1994, 1998, 2003; Sá, 1996), privilegia-a - pelos menos, na etapa inicial relatada neste artigo - por duas razões. A primeira é que essa abordagem provê um critério muito útil para a comparação entre as representações dos três estratos etários, em termos das semelhanças e diferenças entre os conteúdos temáticos que compõem seus respectivos sistemas centrais e periféricos. A segunda razão é que ela permite identificar os conteúdos temáticos que são mais provavelmente ligados à memória coletiva predominante em cada uma das gerações estudadas, em função da sua localização nos sistemas centrais ou "núcleos centrais", como também podem ser chamados das respectivas representações.

\section{Método}

\section{Participantes}

Os sujeitos da pesquisa foram 834 habitantes do Município do Rio de Janeiro, distribuídos em três diferentes amostras, doravante chamadas de "adultos", "jovens" e "idosos". As amostragens dos adultos e dos jovens foram estratificadas por gênero, escolaridade e local de moradia, com base no censo demográfico de 2000 (Instituto Brasileiro de Geografia e Estatística - IBGE, 2003). A terceira amostra foi recrutada em locais de concentração de pessoas idosas, como a Universidade
Aberta da Terceira Idade, da Universidade do Estado do Rio de Janeiro (UERJ), procurando-se manter a proporção de distribuição por gênero apontada pelo censo.

A amostra de adultos, que corresponde à geração que viveu o Regime Militar durante o período crítico de retenção das lembranças - cuja duração foi estreitada nesta pesquisa, para fins de adequação comparativa foi constituída por duzentas pessoas que, no período de 1964 a 1985, tinham entre 15 e 21 anos de idade, ou seja, que estavam na faixa de 34 a 60 anos na ocasião da coleta dos dados, em 2004.

A amostra de jovens foi constituída por 432 pessoas que tinham entre 15 e 21 anos de idade na ocasião da coleta dos dados, em 2003, e que, portanto, nasceram após o fim do Regime Militar ou eram ainda muito crianças quando ele já estava terminando. Alguns resultados relativos exclusivamente a esta amostra foram já publicados por Castro, Sá, Möller e Bezerra (2005) e Sá, Castro, Oliveira e Möller (2005).

A amostra de idosos foi constituída por 202 pessoas que viveram os dois governos Vargas quando tinham entre 15 e 21 anos de idade-um critério relevante para outra pesquisa, sobre a memória da Era Vargas - e que, portanto, já haviam passado do período crítico de retenção de lembranças quando testemunharam o Regime Militar, tendo assim 65 anos ou mais na ocasião da coleta dos dados, em 2005

Considerando que, além da comparação entre as gerações, foi também objetivo deste trabalho a comparação intragrupal, apresentam-se na Tabela 1 as composições das três amostras em termos de gênero (masculino e feminino), nível de escolaridade (fundamental, médio e superior, completos ou incompletos) e orientação política (esquerda, incluindo centro-esquerda; direita, incluindo centro-direita; e sem orientação política definida).

\section{Instrumentos}

O instrumento de coleta dos dados foi um questionário aplicado individualmente aos sujeitos e preenchido pelos pesquisadores. O questionário era constituído de 31 perguntas fechadas e abertas, precedidas por uma tarefa de evocação ou associação livre de palavras (Vergès, 1992; Abric, 2003). Apenas os dados 
Tabela 1. Distribuição das três amostras geracionais em função do gênero, nível de escolaridade e orientação política dos sujeitos. Rio de Janeiro (RJ), 2003, 2004 e 2005.

\begin{tabular}{|c|c|c|c|c|c|c|c|c|c|}
\hline \multirow{2}{*}{ Amostras } & \multicolumn{2}{|c|}{ Gênero } & \multicolumn{3}{|c|}{ Nível de escolaridade } & \multicolumn{3}{|c|}{ Orientação política } & \multirow{2}{*}{ Sujeitos (n) } \\
\hline & Masculino & Feminino & Fundamental & Médio & Superior & Esquerda & Direito & Sem definição & \\
\hline Adultos & 99 & 101 & 90 & 98 & 12 & 75 & 46 & 79 & 200 \\
\hline Jovens & 229 & 203 & 192 & 202 & 38 & 76 & 83 & 273 & 432 \\
\hline Idosos & 89 & 113 & 90 & 58 & 54 & 58 & 68 & 76 & 202 \\
\hline Total & 417 & 417 & 372 & 358 & 104 & 209 & 197 & 428 & 834 \\
\hline
\end{tabular}

relativos a esta tarefa foram objeto de análise para o relato parcial da pesquisa neste artigo.

Os dados obtidos a partir da evocação livre foram as palavras ou expressões que os sujeitos associaram ao termo indutor "Regime Militar". Após a evocação espontânea de até cinco palavras ou expressões, cada sujeito foi solicitado a hierarquizá-las, como propõe Abric (2003), atribuindo peso "1" àquela que julgava mais importante, peso "2" à que considerava seguir-se em importância, e assim por diante.

\section{Análise dos dados}

Uma primeira providência de tratamento dos dados, para fins comparativos, consistiu na padronização das palavras ou expressões que, embora similares, foram evocadas com pequenas diferenças em gênero, número e tempo verbal, ou sob formas sinônimas. Disso resultou um elenco de 432 temas específicos associados à lembrança do Regime Militar. Apenas três desses temas -"forças armadas","época boa"e"época ruim"- resultaram de um processo de categorização mais abrangente, a fim de que compensar a dispersão das palavras que os consubstanciam, como se poderá ver adiante.

Os dados foram tratados com auxílio do programa Ensemble de programmes permettant l'analyse des évocations (EVOC), versão 3 (Vergès, 2000), pelo qual são combinados dois critérios de análise: 1) frequência com que cada tema foi evocado pelo conjunto dos sujeitos; 2) ordem média de importância (OMI) que Ihe foi atribuída, ou seja, a média ponderada dos graus de importância dados ao tema por quantidades variáveis de sujeitos. Essa combinação de critérios possibilita a análise estrutural da representação, que toma expressão gráfica por meio da distribuição dos temas pelos quadrantes de um "quadro de quatro casas", cada um dos quais comportando, em termos aproximativos, uma interpretação teórica distinta.

Nesse sentido, os temas situados no quadrante superior esquerdo, que são os de frequência de evocação mais elevada e de menor ordem média de importância atribuída (o que significa ter maior importância, devido à ponderação utilizada), fornecem a composição mais provável do núcleo central da representação. Os temas situados nos demais quadrantes correspondem ao sistema periférico da representação, embora se possa fazer uma distinção entre eles com base no seu grau de proximidade em relação ao sistema central ou em suas relações características com ele. Assim, os temas situados no quadrante superior direito, também muito frequentes mas considerados menos importantes, compõem uma "primeira periferia", não se afastando a possibilidade de que algum ou alguns de tais temas sejam efetivamente centrais. Já os temas do quadrante inferior direito, pouco frequentes e pouco importantes, fazem mais nitidamente parte do sistema periférico e são designados como uma "segunda periferia". Finalmente, dos temas situados no quadrante inferior esquerdo, pouco frequentes mas considerados muito importantes pelos que os evocam, diz-se que constituem uma "zona de contraste", que pode, segundo Abric (2003), indicar a existência de um subgrupo que sustenta uma representação distinta daquela da maioria do grupo, ou mesmo que esteja em curso um processo de transformação da representação.

\section{Resultados e Discussão}

Apresentam-se sob a forma de "quadros de quatro casas" as configurações temáticas estruturais das representações sociais que configuram a memória histórica do Regime Militar em cada um dos conjuntos 
etários. A discussão comparativa desses resultados baseia-se não apenas no confronto entre tais estruturas temáticas, mas também nas diferenças estatisticamente significativas - superiores a 10\% pelo teste $t$ de Student $(p<0,1)$ - entre as frequências de evocação de determinados temas por cada uma das amostras em relação às demais, mas também, no interior de cada conjunto, por cada um dos subconjuntos diferenciados em termos de nível de escolaridade em relação aos demais e por cada um dos subconjuntos diferenciados em termos de orientação política em relação aos demais.

\section{A memória histórica do Regime Militar pelas diferentes gerações}

As Tabelas 2, 3 e 4 mostram as configurações estruturais das representações sociais que integram, em termos de temas privilegiados, as memórias históricas do Regime Militar construídas pelos adultos, jovens e idosos, respectivamente. Cabe observar que, em cada conjunto, os temas evocados por menos de $5 \%$ dos sujeitos foram descartados da análise, devido à sua reduzida representatividade social.

Tabela 2. Quadro de quatro casas a partir das evocações pelos sujeitos adultos de temas associados ao Regime Militar. Rio de Janeiro (RJ), 2004 ( $n=200$; frequência mínima=10).

\begin{tabular}{|c|c|c|c|c|c|c|}
\hline \multirow{3}{*}{$\begin{array}{l}\text { O.M.I. } \\
\text { Freq Med }\end{array}$} & \multicolumn{6}{|c|}{ Conjunto adultos } \\
\hline & \multirow[b]{2}{*}{ Tema evocado } & \multicolumn{5}{|c|}{$\geq 2,3$} \\
\hline & & Frequência & O.M.I. & Tema evocado & Frequência & O.M.I. \\
\hline \multirow{4}{*}{$\geq 23$} & Ditadura & 80 & 1,600 & Censura & 42 & 2,667 \\
\hline & Mortes & 39 & 2,179 & Forças armadas & 37 & 2,568 \\
\hline & \multirow[t]{2}{*}{ Tortura } & \multirow[t]{2}{*}{23} & \multirow[t]{2}{*}{2,261} & Repressão & 27 & 2,407 \\
\hline & & & & Época ruim & 27 & 2,333 \\
\hline \multirow{7}{*}{$<23$} & Sem liberdade & 20 & 2,214 & Autoritarismo & 11 & 2,455 \\
\hline & Segurança & 18 & 1,722 & Ordem & 19 & 2,368 \\
\hline & Medo & 17 & 2,059 & Prisões & 17 & 2,588 \\
\hline & Abuso de poder & 15 & 1,600 & Violência & 14 & 2,429 \\
\hline & \multirow[t]{3}{*}{ Época boa } & \multirow[t]{3}{*}{14} & \multirow[t]{3}{*}{2,214} & Golpe de estado & 12 & 2,667 \\
\hline & & & & Exílio & 10 & 3,500 \\
\hline & & & & Rigidez & 10 & 2,400 \\
\hline
\end{tabular}

O.M.l.: ordem média de importância; Freq Med: frequência média.

Tabela 3. Quadro de quatro casas a partir das evocações pelos sujeitos jovens de temas associados ao Regime Militar. Rio de Janeiro (RJ), 2003 (n=433; frequência mínima=20).

\begin{tabular}{|c|c|c|c|c|c|c|}
\hline \multirow{3}{*}{$\begin{array}{l}\text { O.M.I. } \\
\text { Freq Med }\end{array}$} & \multicolumn{6}{|c|}{ Conjunto jovens } \\
\hline & \multirow[b]{2}{*}{ Tema evocado } & \multicolumn{5}{|c|}{$\geq 2,5$} \\
\hline & & Frequência & O.M.I. & Tema evocado & Frequência & O.M.I. \\
\hline \multirow{6}{*}{$\geq 57$} & Guerra & 120 & 2,442 & & & \\
\hline & Ditadura & 102 & 2,108 & & & \\
\hline & Mortes & 96 & 2,438 & & & \\
\hline & Forças armadas & 91 & 2,462 & & & \\
\hline & Censura & 67 & 2,284 & & & \\
\hline & Repressão & 65 & 2,292 & & & \\
\hline \multirow{7}{*}{$<57$} & Tortura & 28 & 2,464 & Conflitos & 43 & 3,023 \\
\hline & Opressão & 24 & 2,417 & Armamento & 40 & 2,900 \\
\hline & Autoritarismo & 23 & 2,304 & Violência & 37 & 2,595 \\
\hline & Política & 20 & 2,000 & Prisões & 36 & 2,667 \\
\hline & & & & Polícia & 34 & 2,559 \\
\hline & & & & Medo & 20 & 3,250 \\
\hline & & & & Época ruim & 20 & 3,150 \\
\hline
\end{tabular}


Tabela 4. Quadro de quatro casas a partir das evocações pelos sujeitos idosos de temas associados ao Regime Militar. Rio de Janeiro (RJ), 2005 ( $n=202$; frequência mínima=10).

\begin{tabular}{|c|c|c|c|c|c|c|}
\hline \multirow{3}{*}{$\begin{array}{l}\text { O.M.I. } \\
\text { Freq Med }\end{array}$} & \multicolumn{6}{|c|}{ Conjunto idosos } \\
\hline & \multirow{2}{*}{$\frac{<2,6}{\text { Tema evocado }}$} & \multicolumn{5}{|c|}{$\geq 2,6$} \\
\hline & & Frequência & O.M.I. & Tema evocado & Frequência & O.M.I. \\
\hline \multirow{4}{*}{$\geq 27$} & Ditadura & 56 & 1,643 & & & \\
\hline & Censura & 37 & 2,459 & & & \\
\hline & Época boa & 37 & 2,108 & & & \\
\hline & Época ruim & 30 & 2,267 & & & \\
\hline \multirow{9}{*}{$<27$} & Ordem & 26 & 2,038 & Repressão & 26 & 2,692 \\
\hline & Violência & 24 & 2,500 & Prisões & 19 & 3,211 \\
\hline & Tortura & 21 & 2,238 & Autoritarismo & 17 & 2,706 \\
\hline & Disciplina & 20 & 2,100 & Forças armadas & 17 & 2,647 \\
\hline & Segurança & 19 & 2,316 & Perseguição & 17 & 2,882 \\
\hline & Opressão & 16 & 2,375 & Mortes & 16 & 3,188 \\
\hline & Medo & 13 & 2,077 & Poder militar & 11 & 2,636 \\
\hline & Menos violência & 13 & 2,154 & Respeito & 10 & 2,600 \\
\hline & Sem liberdade & 13 & 2,000 & Rigidez & 10 & 2,900 \\
\hline
\end{tabular}

O.M.I: ordem média de importância; Freq Med:frequência média.

Segundo Abric (1994), duas ou mais representações sociais serão diferentes apenas se os seus respectivos sistemas centrais tiverem composições temáticas nitidamente distintas. É isto o que, de fato, acontece com as três configurações representacionais acima, nas quais o único elemento comum aos seus respectivos núcleos centrais é "ditadura". Por outro lado, este não deixa de ser um importante elemento unificador da memória histórica que a sociedade carioca guarda ou cultiva do Regime Militar, que desafia qualquer eventual esforço que se desenvolva na arena política no sentido de caracterizá-lo de outra maneira que não como uma ditadura.

O núcleo central da representação dos adultos (que viveram o Regime Militar quando eram jovens, de modo que as marcas que a ditadura imprimiu à vida social se integraram à sua memória geracional) é conciso, crítico e acusador "ditadura", "mortes" e "tortura". Esse quadro completa-se com os temas da primeira periferia, que, além de "forças armadas" (que nomeia genericamente os agentes mais diretos de sustentação do Regime Militar), inclui "censura","repressão"e tudo o mais que tornou aquele período uma "época ruim". Esta categoria, "época ruim", engloba outros juízos e aspectos negativos que não aqueles nomeados especificamente, dentre os quais se destacam: ruim, muito ruim, péssimo, péssimo para o país, período negro da história do país, atrapalhou a vida de todo mundo, horror para o povo, época mais infeliz que o Brasil passou, época difícil para os jovens, não prestou, só prejuízo, não havia desenvolvimento, o povo não foi ajudado, custo de vida alto, dinheiro era pouco, os militares não fizeram um bom governo, deixou cicatrizes no Brasil, durou muito, parecia que não ia acabar, que bom que acabou, tomara que nunca volte.

Dentre as três representações, a dos sujeitos adultos é a que apresenta a configuração estrutural menos dispersa, visto que os temas que compõem o seu quadro de quatro casas englobam $70 \%$ de todos os temas evocados por essa amostra, enquanto os percentuais relativos às duas outras amostras encontram-se entre 50 e 60\%. Isso quer dizer que a memória histórica cuja construção fez parte do próprio processo de formação daquela coorte geracional tende para uma síntese das experiências e informações em poucos temas principais, evitando as redundâncias e as associações indiretas. Sugere também que, em tal estrato etário, um quadro reduzido de memórias coletivas ou seja, construídas a partir da interação social efetiva, predomina sobre as memórias comuns, naturalmente numerosas, dispersas e circunstanciais.

Quanto aos jovens, que não viveram sob o Regime Militar, a memória apropriada que se manifesta em sua representação compartilha os temas "ditadura" e 
"mortes" com a dos adultos, mas acima destes introduz o tema genérico "guerra". As "mortes" que acreditam ter ocorrido nessa "guerra" são anônimas e talvez até mais numerosas do que aquelas que os jovens da geração anterior identificavam uma a uma, principalmente durante os "anos de chumbo", em um esforço de ruptura do sigilo oficial em que elas eram encerradas. A representação dos jovens confere ainda centralidade aos temas "censura","forças armadas"e "repressão", que estão na primeira periferia da representação dos adultos.

Voltando ao tema "guerra", cabe observar que, além de apontar equivocadamente para uma guerra civil que não houve, ele pode ter um sentido dúbio na evocação, visto que a suposta existência de um estado de guerra foi muito usada pela ditadura militar para justificar as medidas de exceção, como a censura, a repressão, a tortura e, enfim, as mortes. Dado que esse tema, além de ter sido o mais evocado pelos jovens, foi minimamente evocado pelos sujeitos das duas outras amostras em termos de significância estatística, não parece improvável que entre as fontes das quais os jovens apropriaram sua memória estejam os discursos de eliminação de culpas do passado, pela alusão a uma "guerra" que hoje, dizem, deve-se lamentar, mas na qual tudo podia acontecer.

Os jovens foram ainda praticamente os únicos sujeitos a evocar os temas "armamento", "polícia" e"conflitos", que integram a periferia da sua representação. Estes temas correspondem à face urbana mais concreta e visível do período a qual, por isso mesmo, tem suas imagens reproduzidas na mídia com alguma frequência e que envolveu maciçamente os jovens estudantes de então. A disponibilidade das imagens e uma identificação com a juventude em geral podem talvez responder pelo privilégio dado pelos jovens de hoje a esses temas. Tais temas, por outro lado, não persistiram na memória dos jovens que os testemunharam e sofreram, os quais parecem ter preferido englobá-los sob o tema genérico da"repressão".

Os idosos desta pesquisa, assim como os adultos quando jovens, testemunharam a vigência do Regime Militar, porém quando eles próprios já eram adultos. A comparação entre as representações de ambas as amostras evidencia que elas construíram memórias bastante distintas da mesma época histórica. A principal distinção e isso vale também para a memória dos jovens - é a cisão ou ambivalência do sistema central da represen- tação dos idosos, ou seja, a avaliação do regime simultaneamente como uma "época boa"e como uma "época ruim", complementando os temas consensuais da"ditadura" e da "censura". Teoricamente, as representações sociais bem consolidadas suportam a heterogeneidade, mas apenas em seus sistemas periféricos, não nos sistemas centrais. Falta, pois, à memória dos idosos a consistência encontrada nas duas outras faixas etárias.

Uma segunda diferença entre as representações dos demais estratos e a dos idosos é que a consideração do Regime Militar como uma "época boa" é significativamente superior nesta última. Esta categoria, "época boa", engloba outros juízos e aspectos positivos que não aqueles nomeados especificamente, dentre os quais destacam-se: bom, muito bom, ótimo, muito melhor que agora, melhor não podia ser, bom período para o país, o Brasil se desenvolveu, praticamente só aconteceram coisas boas, época boa de se viver, era cem por cento, havia mais trabalho, tinha salário digno, educação era melhor, custo de vida estava estável, houve fartura, na ditadura o povo tinha uma vida melhor, hoje acredito que é melhor que a democracia, tenho saudades do regime, era feliz e não sabia, essa época tinha que voltar, faz falta, tomara que volte um dia. Os idosos distinguem-se ainda dos outros conjuntos etários pela localização dos temas "mortes"e "forças armadas"apenas na segunda periferia da sua representação, enquanto o primeiro desses temas é central tanto na representação dos adultos quanto na dos jovens, e o segundo, também central para os jovens, está na primeira periferia da representação dos adultos.

Grosso modo, portanto, tomando por base a memória crítica e acusadora dos adultos, o Regime Militar parece ser representado de forma ainda mais negativa pelos jovens e de forma bem menos rigorosa pelos idosos. A rigor, entretanto, nas três representações, consideradas em suas tendências majoritárias, detecta-se a possível existência de uma representação minoritária, que se opõe àquela sustentada pela maioria. Isso parece bem evidente na representação dos idosos, que, além de privilegiar centralmente o tema "época boa", abriga em sua zona de contraste temas que parecem de alguma forma favoráveis ao Regime Militar, como "ordem", "disciplina", "segurança" e "menos violência", seguidos ainda de "respeito" na segunda periferia. A representação dos adultos, por sua vez, abre espaço para os temas "segurança"e mesmo "época boa"na zona de contraste, e para"ordem"na segunda periferia. Pare- 
cendo confirmar o caráter maximamente crítico da representação dos jovens, nenhuma dessas concessões pode ser visualizada no seu quadro de quatro casas, mas, abaixo do nível de $4 \%$ dos temas evocados, encontrar-se-iam na zona de contraste os temas "disciplina","ordem", "respeito", "segurança" e "defesa do país".

\section{As diferenças na memória de cada geração em função da orientação política}

Uma das características mais marcantes da memória social é que, embora o passado em si mesmo constitua a sua matéria-prima, o processo psicossocial da sua construção encontra-se grandemente subordinado aos interesses e necessidades do presente. Pelo menos no que se refere à memória de regimes políticos, tais interesses e necessidades consubstanciam-se na orientação política predominante nos conjuntos ou subconjuntos sociais em cujo âmbito são elaboradas as representações sociais do passado.

Neste trabalho distinguiram-se três tipos de orientações políticas: 1) esquerda, englobando os sujeitos que se declararam de esquerda ou de centro-esquerda; 2) direita, englobando os sujeitos que se declararam de direita ou de centro-direita; 3) sem definição política, englobando os sujeitos que declararam não ter uma orientação política definida. A análise das influências relativas desses diferentes subconjuntos para a configuração da representação de cada conjunto etário não se baseia nas suas contribuições em termos das frequências absolutas de evocação dos temas, mas sim nas diferenças estatisticamente significativas entre elas, proporcionadas pelo programa EVOC, por meio da identificação dos temas nos quais a diferença relativa entre dois dados subconjuntos é superior a 10\% segundo o teste $t$ de Student $(p<0,1)$. Ficam assim neutralizadas as defasagens proporcionais na constituição das amostras e evidenciam-se os temas mais caracteristicamente produzidos por um ou outro tipo de orientação política. No conjunto dos adultos, cuja representação do Regime Militar é mais concisa e menos dispersa, os subconjuntos de orientações políticas distintas apresentaram poucas diferenças significativas. Nenhuma diferença de contribuição foi encontrada na constituição do sistema central da representação. Já a presença de "forças armadas"na segunda periferia deve-se basicamente à contribuição do subconjunto sem definição política, o que sugere que uma boa parte das evocações que compõem essa categoria possa ter sido produzida menos como uma nomeação das forças de sustentação do regime como fica claro na evocação do tema "poder militar", muito reduzida em todas as amostras e mais devido a uma tendência à repetição parcial do termo indutor e de alguns de seus componentes e termos afins, como mostram as evocações que compõem aquela categoria: "forças armadas, exército, marinha, aeronáutica, militares, general, coronel, capitão, tenente, sargento, soldado, organização militar, base militar, batalhões, quartéis, cavalaria, fuzileiro naval, paraquedista". Por outro lado, os temas "segurança"e "ordem", que podem configurar o surgimento de uma representação minoritária e contrastante com a da maioria, foram evocados tipicamente pelo subconjunto de direita, quando em comparação com os outros dois.

No conjunto dos jovens, encontram-se diferenças mais marcantes, a começar pela contribuição significativa dos subconjuntos sem orientação definida e de direita sem diferença entre ambos para a centralidade dos temas "guerra"e"mortes", quando em comparação com o subconjunto de esquerda, o que tende a corroborar as interpretações antes aventadas para o privilégio concedido a esses temas pelos jovens. Por outro lado, a evocação do tema "ditadura" é comum aos jovens de direita e de esquerda, mas significativamente superior nestes últimos, em comparação com o subconjunto sem orientação definida, o que sugere que o alcance do seu pleno significado exige algum tipo de engajamento político. Dois outros temas centrais "censura" e "repressão" são contribuições significativas dos jovens de esquerda em comparação com os dos dois outros subconjuntos, que não diferem entre si na frequência de sua evocação. Finalmente, embora já fora do sistema central, a evocação do tema "tortura" não distingue entre os subconjuntos de esquerda e de direita, mas em ambos ela é significativamente superior à dos jovens sem orientação política definida, que tendem a não registrar essa realidade factual na sua memória histórica do Regime Militar.

No conjunto dos idosos, as diferenças estatisticamente significativas encontradas podem explicar, pelo menos em parte, a falta de consistência na sua representação do Regime Militar. De fato, na composição do núcleo central, apenas o tema "época ruim" foi evocado sem diferenças entre os três subconjuntos. Já o tema "ditadura" foi uma contribuição típica dos sujeitos de esquerda, cuja evocação foi significativamente superior 
às dos dois outros subconjuntos, que pouco diferiram entre si nesse aspecto. Da mesma forma, a esquerda evocou a "censura" com uma frequência significativamente superior à da direita, embora não se tenham revelado diferenças nas outras comparações. Por outro lado, a concessão de um caráter central ao tema"época boa" deve-se aos subconjuntos de direita e sem orientação definida, de forma indiferenciada entre si e nitidamente distinta do subconjunto de esquerda. Enfim, já na periferia, dois pares opostos de temas - "repressão"e "tortura", por um lado, e"ordem"e "segurança", por outro - foram produções características, respectivamente, da esquerda e da direita, em uma comparação polarizada, que recebem tanto uma quanto a outra contribuições indiscriminadas dos sujeitos sem orientação política definida.

\section{As diferenças na memória de cada geração em função do nível de escolaridade}

Como já argumentado por Halbwachs (1950/ 2004), memória e conhecimento sociais encontram-se estreitamente imbricados em qualquer esforço de reconstrução do passado. Ou seja, as pessoas dificilmente são capazes de distinguir entre lembranças efetivas do passado e informações obtidas acerca desse passado. O primeiro dia de alguém na escola é o exemplo clássico de que se vale Halbwachs: sabe-se que ele existiu, embora se possa não ter retido nenhuma lembrança específica desse dia; não obstante, ele integra legitimamente a memória autobiográfica dessa pessoa.

Nesse sentido, as informações que são obtidas sobre um dado período histórico, seja por ocasião da ocorrência dos fatos ou posteriormente, desempenham um importante papel na construção da memória histórica de qualquer conjunto social. E, como a obtenção de informações por exemplo, o acesso aos fatos noticiados pela mídia quando da sua ocorrência ou a análises escritas posteriormente depende basicamente do nível cultural ou de escolaridade que caracteriza um dado conjunto de pessoas, segue-se que diferenças em tal nível podem explicar, pelo menos em parte, a produção de diferentes representações sociais do passado.

Para os propósitos deste trabalho, os sujeitos de cada conjunto etário foram alocados em três diferentes subconjuntos segundo o nível de escolaridade: 1) fundamental, completo ou incompleto; 2) médio, completo ou incompleto; 3) superior, completo ou incompleto. Assim como no caso das diferenças em orientação política, a análise das influências relativas desses diferentes subconjuntos para a configuração da representação de cada conjunto etário não se baseou nas suas contribuições em termos das frequências absolutas de evocação dos temas, mas sim nas diferenças estatisticamente significativas entre elas.

No conjunto dos adultos, como a amostra de sujeitos com nível superior de escolaridade foi pouco numerosa, só foi possível evidenciar a frequência maior de evocação por este subconjunto do tema"repressão" em relação aos dois outros subconjuntos, em termos de significância estatística. Entretanto, na comparação entre os sujeitos de nível fundamental e os de nível médio, fica claro que estes últimos evocam de forma significativamente mais frequente os temas centrais "ditadura","mortes"e"tortura", bem como os temas periféricos "censura" e "repressão", igualmente críticos. Enquanto isso, os sujeitos de nível fundamental foram os que tipicamente privilegiaram os temas "segurança" e"época boa"da zona de contraste, o que parece apontar para um acesso deficiente à informação ou para uma exposição quase exclusiva à informação oficial predominante durante a sua juventude.

No conjunto dos jovens, as diferenças observadas são mais esclarecedoras, a começar pela composição do sistema central. O tema "guerra" foi evocado exclusivamente pelos sujeitos de níveis médio e fundamental, sem diferença significativa entre ambos. $\mathrm{Na}$ evocação dos temas "ditadura", "censura" e "repressão", as frequências do subconjunto de nível superior superaram significativamente as dos subconjuntos de níveis médio e fundamental, bem como as do primeiro destes superam as do segundo. As frequências totais dos temas "mortes" e"forças armadas" devem-se quase exclusivamente aos sujeitos de níveis médio e fundamental, situando-se as destes últimos, em ambos os casos, significativamente acima das dos primeiros. Na periferia da representação, os temas de natureza mais crítica "tortura", "opressão"e"violência"foram privilegiados pelo subconjunto de nível superior, em proporções significativamente superiores ao que fazem os outros dois subconjuntos. Tanto em relação a estes quanto aos demais temas periféricos cuja evocação pelos sujeitos de nível superior foi muito reduzida para permitir a comparação não há diferenças entre os sujeitos de nível médio e os de nível fundamental, com exceção do tema 
"polícia", que foi significativamente mais evocado pelos últimos.

No conjunto dos idosos, não se encontraram diferenças significativas entre as frequências de evocação dos temas centrais pelos subconjuntos de nível superior e de nível médio. Os sujeitos de nível superior superaram, entretanto, os de nível fundamental na evocação do tema "ditadura", e superaram tanto estes quanto os de nível médio na evocação do tema periférico "repressão". O resultado mais esclarecedor nesse estrato etário mostra que a evocação do tema central "época boa" que divide as preferências dos idosos com o tema igualmente central "época ruim" deve-se maciçamente aos sujeitos de nível fundamental, com diferenças estatisticamente significativas em relação aos dois outros níveis.

\section{Considerações Finais}

Não é correto que o povo brasileiro não tenha memória, como se afirma frequentemente. Ele tem, sim, uma memória, que pode construir a partir de suas vivências geracionais, de suas condições socioculturais e de sua participação política, com toda a diversidade que as recobre, bem como do acesso igualmente diferenciado à educação, à história, à arte e à literatura.

No que se refere ao Regime Militar e à população do município do Rio de Janeiro, como representado nas amostras deste estudo, o processo psicossocial de construção da memória histórica mostrou-se sensível a todos os condicionantes que foram arrolados, e as evidências disso podem ser facilmente sumarizadas.

A principal dessas evidências refere-se ao que foi flagrantemente comum nas memórias das três gerações estudadas: o Regime Militar foi uma ditadura. Isto, que poderia ser tomado como uma simples constatação descritiva, tem importância porque identifica uma resistência popular espontânea e generalizada às tentativas de caracterizar o regime de forma mais amena, como se tivesse consistido em um mero ciclo de presidentes militares. Para além dessa unanimidade, o que se encontrou foi principalmente uma série de diferenças que tornam a memória histórica do Regime Militar uma realidade psicossocial complexa.

Para interpretar essas diferenças, assume-se aqui o pressuposto de que a memória do Regime Militar em sua versão historicamente mais fidedigna e promotora de cidadania responsável não é neutra ou apenas descritiva, mas também valorativa e fortemente crítica. Constatou-se que uma construção da memória nesse sentido é característica dos sujeitos adultos, cuja geração foi, mais do que as outras, marcada pela vivência do regime, em função de estarem então construindo a sua própria identidade geracional. A rigor, a geração seguinte, que não viveu durante o regime, pode ter parecido ainda mais crítica, devido aos temas mais numerosos e diversificados que associou a este período, mas essa aparência não resiste ao exame da natureza do mais evocado desses temas uma guerra, que não aconteceu, mas que era aludida pelos porta-vozes da ditadura para justificar o estado de exceção. Por outro lado, os idosos, que viveram o regime quando já eram adultos e dotados de interesses e necessidades bem definidos e diferenciados, em função de suas inserções sociais específicas, refletem essas diferenças na forma valorativa ambivalente com que lembram o Regime Militar.

Além do fato de as experiências vividas por diferentes gerações serem naturalmente distintas, cabe assinalar a escassez contemporânea de recursos culturais orientados para o consumo de um público mais amplo, como o cinema e a televisão. Em relação ao Regime Militar, são poucas as produções desses gêneros que têm alimentado a memória popular, das quais se podem destacar: a) os filmes "Pra frente, Brasil", de R. Farias, em 1982; "Nunca fomos tão felizes", de M. Salles, em 1984; "Lamarca”, de S. Rezende, em 1994; "O que é isso, companheiro?", de B. Barreto, em 1997;"Zuzu Angel", de S. Rezende, em 2006; e "O ano em que meus pais saíram de férias", de C. Hamburger, em 2006; b) a minissérie"Anos rebeldes", de G. Braga, exibida pela Rede Globo em julho e agosto de 1992.

Passadas mais de duas décadas do fim do Regime Militar, não existem locais, monumentos ou construções arquitetônicas que constituam marcos notórios de episódios significativos do período e que possam ser amplamente visitados pela população na constituição de "lugares de memória" (Nora, 1997). Embora isso seja mais verdadeiro em relação aos fatos e personagens cuja lembrança desabonaria o regime, cabe reconhecer que tampouco são muitos aqueles que o glorificariam, carecendo ambos de quadros sociais de referência para sustentar sua memória. Na acepção ampla do conceito de "lugares de memória", incluir-se-iam também os produtos de movimentos sociais de rememoração crítica do regime, dos quais 
apenas aqueles ensejados pelo grupo "Tortura Nunca Mais" parecem ter maior repercussão. Além disso, durante o regime, as manifestações culturais de contestação usualmente reprimidas, como as peças teatrais e as músicas de compositores engajados - como Chico Buarque, para citar um ícone usavam, para iludir a censura, metáforas que se encontravam fora do alcance de entendimento das massas populares. Assim, não deve surpreender que variáveis como nível de escolaridade e orientação política esta última já possivelmente sedimentada em tradições familiares ou grupais específicas tenham se mostrado decisivas na explicação das diferenças encontradas no âmbito de cada um dos estratos etários que compuseram a amostra global da pesquisa.

Embora se tenha podido observar algum efeito dessas variáveis na memória dos adultos, cuja construção parece ter realmente se beneficiado do testemunho dos fatos durante o "período crítico" da adolescência e da juventude, é na construção das memórias dos dois outros conjuntos etários que se fazem sentir inequivocamente as influências do nível de escolaridade e da orientação política. A rememoração de uns poucos resultados, a seguir, é suficiente para demonstrar isso.

Na evocação do tema crítico "ditadura", que foi central e comum a todas as amostras, pôde-se perceber tanto entre os jovens quanto entre os idosos uma espécie de gradiente decrescente de contribuição, a qual, por um lado, diminui desde a esquerda até a ausência de orientação política e, por outro lado, diminui desde o nível superior até o fundamental. A "guerra", que é um tema dúbio mas marcante entre os jovens, foi evocada caracteristicamente pelos subconjuntos de direita e sem orientação definida e pelos subconjuntos de níveis médio e fundamental, quase sem nenhuma participação dos subconjuntos de esquerda e de nível superior. A "época boa", que marca uma estranha cisão na memória dos idosos, deve nitidamente sua centralidade apenas aos sujeitos de direita e sem orientação política e aos sujeitos de nível fundamental.

Finalmente, no conjunto dos jovens a geração que mais deve preocupar a sociedade brasileira em termos de uma construção conjunta da memória e da cidadania, temas críticos como "ditadura", "opressão", "repressão", "censura" e "tortura" foram lembrados de forma significativamente mais reduzida pelos subcon- juntos sem orientação política e de nível fundamental, em relação aos de esquerda e de direita e aos de nível superior e médio. Tudo leva a crer que não Ihes falta apenas o conhecimento dos fatos concretos a que aqueles temas se referem, mas também o domínio do próprio vocabulário crítico pelo qual se descortinam as dimensões mais duras e cruéis do Regime Militar.

A memória histórica do Regime Militar no Rio de Janeiro é aquela que a sua população foi capaz de construir. Sua característica mais importante é o repúdio que ela nitidamente vota a esse passado, o que constitui uma garantia de resistência e oposição popular a qualquer eventual tentativa de reedição de um regime de exceção como aquele no país. Embora essa construção comporte também ambiguidades e ambivalências, isso não constitui uma marca necessariamente permanente ou imutável da memória social. Constatou-se que esses aspectos estão associados não apenas à vivência do passado em si inclusive, uma das gerações estudadas sequer chegou a testemunhá-lo, mas principalmente a circunstâncias presentes, como os baixos níveis de escolaridade e a carência de educação política da maior parte da população. O passado, por certo, não muda, mas a memória que a sociedade construiu dele pode ser reconstruída, e tal reconstrução será naturalmente caudatária do sucesso que venham a ter as políticas públicas voltadas para a educação e o desenvolvimento da cidadania brasileira.

\section{Referências}

Abric, J. C. (1994). Les représentations sociales: aspects théoriques. In J-C. Abric (Org.), Pratiques sociales et représentations (pp.11-35). Paris: Presses Universitaires de France.

Abric, J. C. (1998). A abordagem estrutural das representações sociais. In A. S. P. Moreira \& D. C. Oliveira (Orgs.), Estudos interdisciplinares de representação social (pp.27-38). Goiânia: AB Editora.

Abric, J. C. (2003). La recherche du noyau central et de la zone muette des représentations sociales. In J. C. Abric (Org.), Méthodes d'étude des représentations sociales (pp.59-80). Ramonville Saint-Agne: Érès.

Castro, R. V., Sá, C. P., Möller, R. C., \& Bezerra, F. C. C. (2005). O esquecimento social na representação do Regime Militar por jovens na cidade do Rio de Janeiro. Textos completos da IV Jornada Internacional e da II Conferência Brasileira sobre Representações Sociais (pp.1298-1314). João Pessoa. 
Conway, M. A. (1995). Autobiographical knowledge and autobigraphical memories. In D. C. Rubin (Org.), Remembering ourpast:studies in autobiographicalmemory (pp.67-93). Cambridge: Cambridge University Press.

Conway, M. A. (1998). El inventario de la experiencia: memoria e identidad. In D. Páez, J. F. Valencia, J. W. Pennebaker, B. Rimé \& D. Jodelet (Orgs.), Memorias colectivas deprocesos culturales y políticos (pp.49-82). Bilbao: Universidad del País Vasco.

D’Araujo, M. C., Soares, G. A. D., \& Castro, C. (1994). Os anos de chumbo: a memória militar sobre a repressão. Rio de janeiro: Relume Dumará.

Dreifuss, R. A. (1981). 1964: a conquista do Estado. Petrópolis: Vozes.

Gaspari, E. (2002a). A ditadura envergonhada. São Paulo: Companhia das Letras.

Gaspari, E. (2002b). A ditadura escancarada. São Paulo: Companhia das Letras.

Gaspari, E. (2004a). A ditadura derrotada. São Paulo: Companhia das Letras.

Gaspari, E. (2004b). A ditadura encurralada. São Paulo: Companhia das Letras.

Gorender, J. (1987). Combate nas trevas: a esquerda brasileira: das ilusões perdidas à luta armada. São Paulo: Ática.

Halbwachs, M. (1994). Les cadres sociaux de la mémoire. Paris: Albin Michel. (Originalement publié et 1925).

Halbwachs, M. (2004). A memória coletiva. São Paulo: Centauro. (Originalmente publicado em 1950).

Instituto Brasileiro de Geografia e Estatística. (2003). Censo demográfico 2000. Rio de Janeiro, IBGE. Recuperado em 2003 jan 25, disponível em http://www.ibge.gov.br/ censo/default.php

Jedlowski, P. (2001). Memory and sociology: themes and issues. Time \& Society, 10 (1), 29-44.

Jodelet, D. (1984). Représentations sociales: phénomènes, concept et théorie. In S. Moscovici (Org.), Psychologie sociale (pp.357-378). Paris: Presses Universitaires de France.

Jodelet, D. (1989). Représentations sociales: un domaine en expansion. In D. Jodelet (Org.), Les représentations sociales (pp.31-61). Paris: Presses Universitaires de France.

Jodelet, D. (1992). Mémoire de masse: le côté moral et affective de I'histoire. Bulletin de Psychologie, 45 (405), 239-256.

Mannheim, K. (1982). O problema sociológico das gerações. In M. M. Foracchi (Org.), Karl Mannheim (pp.67-95). São Paulo: Ática. (Originalmente publicado em 1952).

Moreira Alves, M. (1984). Estado e oposição no Brasil (19641984). Petrópolis: Vozes.

Moscovici, S. (1976). La Psychanalyse, son imageet son public. Paris: Presses Universitaires de France.
Moscovici, S. (1984). The phenomenon of social representations. In S. Moscovici \& R. M. Farr (Orgs.), Social representations (pp.3-69). Cambridge: Cambridge University Press.

Nora, P. (1997). Entre mémoire et histoire: la problématique des lieux. In P. Nora (Org.), Les lieux de mémoire (pp.23-43). Paris: Gallimard.

Pennebaker, J. W., \& Basanik, B. (1998). Creación y mantenimiento de memorias colectivas. In D. Páez, J. F. Valencia, J. W. Pennebaker, B. Rimé \& D. Jodelet (Orgs.), Memorias colectivas de procesos culturales y políticos (pp.31-47). Bilbao: Universidad del País Vasco.

Sá, C. P. (1996). Núcleo central das representações sociais. Petrópolis: Vozes.

Sá, C. P. (1998). A construção do objeto de pesquisa em representações sociais. Rio de Janeiro: EdUerj.

Sá, C. P. (2005). As memórias da memória social. In C. P. Sá (Org.), Memória, imaginário e representações sociais (pp.63-86). Rio de Janeiro: Ed. Museu da República.

Sá, C. P. (2007). O campo de estudo da memória social: uma perspectiva psicossocial. Psicologia: Reflexão \& Crítica, 20 (2), 290-295.

Sá, C. P. (2008). Les défis d'une psychologie sociale de la mémoire. In B. Madiot, E. Lage \& A. Arruda (Orgs.). Une approcheengagée em psychologiesociale:l'ouevrede Denise Jodelet. Ramonville Saint-Agne: Éditions Érès.

Sá, C. P., Castro, R. V., Oliveira, D. C., \& Möller, R. C. (2005). A memória social do Regime Militar entre jovens na cidade do Rio de Janeiro: seu lugar na estrutura representacional. Textos completos da IV Jornada Internacional e da II Conferência Brasileira sobre Representações Sociais (pp.1117-1123). João Pessoa.

Santos, A. M., Neves, G. P., Machado, H. F., \& Gonçalves, W. S. (2002). História do Brasil: de terra ignota ao Brasil atual. Rio de Janeiro: LogOn.

Schuman, H., Belli, R. F., \& Bischoping, K. (1998). La base generacional del conocimiento histórico. In: D. Páez, J. F. Valencia, J. W. Pennebaker, B. Rimé \& D. Jodelet (Orgs.), Memorias colectivas de procesos culturales y políticos (pp.83-120). Bilbao: Universidad del País Vasco.

Skidmore, T. E. (1998). Uma história do Brasil. São Paulo: Paz e Terra.

Ventura, Z. (1988). 1968: o ano que não terminou. Rio de Janeiro: Nova Fronteira.

Vergès, P. (1992). L'évocation de l'argent: une méthode pour la definition du noyau central de la représentation. Bulletin de Psychologie, 45 (405), 203-20.

Vergès, P. (2000). EVOC:ensemble de programmes permettant l'analyse desévocations: manuelversion 3. Aix-en-Provence: LAMES.

Recebido em: 7/2/2007

Versão final reapresentada em: 13/3/2008

Aprovado em: 25/6/2008 
